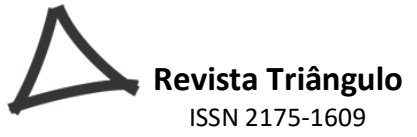

DOI: https://doi.org/10.18554/rt.v10i2.2578

\title{
PACTO NACIONAL PELA ALFABETIZAÇÃo NA IDADE CERTA (PNAIC): MAPEANDO SUA CONTRIBUIÇÃO PARA A FORMAÇÃO CONTINUADA DE PROFESSORES ALFABETIZADORES
}

\author{
PACTO NACIONAL PELA ALFABETIZAÇÃO NA IDADE CERTA (PNAIC): MAPPING ITS \\ CONTRIBUTION TO THE CONTINUED TRAINING OF LITERACY NATIONAL PACT FOR \\ TEACHERS
PACTO NACIONAL PELA ALFABETIZAÇÃO NA IDADE CERTA (PNAIC): MAPEANDO SU CONTRIBUCIÓN PARA LA FORMACIÓN CONTINUA DE MAESTROS

Lais Suzana Kurutz Asquidamini. E-mail: lais_suzani@hotmail.com

Rosana Beatriz Ansai. E-mail: ansairosana@yahoo.com.br

Kelen dos Santos Junges. E-mail: prof.kjunges@gmail.com Universidade Estadual do Paraná - Campus de União da Vitória - UNESPAR/FAFIUV

\begin{abstract}
RESUMO
O presente texto apresenta pesquisa realizada com o objetivo de investigar a contribuição da política do Pacto Nacional pela Alfabetização na Idade Certa (PNAIC) para a formação continuada de professores alfabetizadores. $\mathrm{O}$ estudo teve caráter exploratório o qualitativo, apoiado em pesquisa de campo. A coleta de dados foi constituída por um questionário semiestruturado composto por nove perguntas. Os dados foram analisados, categorizados e sistematizados em gráficos e tabelas. Considera-se que o PNAIC contribui para a formação dos professores alfabetizadores, trazendo novas metodologias que auxiliam na prática pedagógica aplicada em sala de aula, influenciando positivamente a aprendizagem dos alunos nos três primeiros anos do ensino fundamental.
\end{abstract}

PALAVRAS-CHAVE: Formação continuada de professores. Pacto Nacional pela Alfabetização na Idade Certa - PNAIC. Alfabetização.

\section{ABSTRACT}

The present text presents research carried out with the objective of investigating the contribution of the Continuing Education of literacy teachers from the policy of the "Pacto Nacional pela Alfabetização na Idade Certa" (PNAIC). The Study Was Exploratory and qualitative, supported by field research. The data collection consisted of a semistructured questionnaire composed of nine questions. Data were analyzed, categorized and systematized in charts and tables. It is considered that the PNAIC contributes to the training of literacy teachers, bringing new methodologies that help in the pedagogical practice applied in the classroom, positively influencing the learning of students in the first three years of elementary school.

KEYWORDS: CONTINUING EDUCATION OF TEACHERS. Pacto Nacional pela Alfabetização na Idade Certa” - PNAIC. LITERACY. 


\section{Revista}

\section{Triângulo}

El presente texto presenta una investigación realizada con el objetivo de investigar la contribución de la política del "Pacto Nacional pela Alfabetização na Idade Certa" (PNAIC) para la formación continua de maestros alfabetizadores. El estudio tuvo carácter exploratorio y cualitativo, apoyado en la investigación de campo. La recolección de datos fue constituida por un cuestionario semiestructurado compuesto por nueve preguntas. Los datos fueron analizados, categorizados y sistematizados en gráficos y tablas. Se considera que el PNAIC contribuye para la formación de los maestros alfabetizadores, trayendo nuevas metodologías que auxilian en la práctica pedagógica aplicada en la clase, influyendo positivamente el aprendizaje de los alumnos en los tres primeros años de la enseñanza fundamental.

PALABRAS-CLAVE: Formación continua de profesores. "Pacto Nacional pela Alfabetização na Idade Certa". Alfabetización.

\section{INTRODUÇÃO}

1.1 A importância da formação continuada para os professores alfabetizadores

O sistema educacional atual necessita de novos métodos que complementem a formação dos professores, trazendo novas propostas e metodologias para trabalhar e aplicar em sala de aula. A implantação de novas formas de ensino faz com que o aluno tenha mais interesse e curiosidade sobre os conteúdos propostos. Assim, a formação continuada tem suma importância, pois com ela há possibilidade da troca de experiências, debates sobre os conteúdos e melhores concepções de ensino, que estimulam e incentivam o interesse dos professores pela prática docente.

O desenvolvimento especializado de professores é uma necessidade premente que se configura como uma política de valorização pessoal e profissional destes profissionais e, consequentemente, das instituições escolares, uma vez que supõe condições de trabalho, propiciando formação contínua dos professores, do local de trabalho, em redes de autoformação e em parceria com outras instituições de formação (LIMA; BARRETO; LIMA, 2007).

Em julho de 2012, com a Portaria n. ${ }^{\circ}$ 867, de 4 de julho de 2012, o Ministério da Educação (MEC) instituiu no Diário oficial da União, o Pacto Nacional pela Alfabetização na Idade Certa (PNAIC). Este Programa tem como principal finalidade contribuir para a melhoria da qualidade do processo de ensino e aprendizagem no ciclo de alfabetização nos anos iniciais do Ensino Fundamental.

No contexto do presente estudo é relevante questionar: qual a contribuição da formação promovida pelo Pacto Nacional pela Alfabetização na Idade Certa (PNAIC) para a 


\section{Revista}

\section{Triângulo}

reflexão e melhoria das práticas pedagógicas utilizadas em sala de aula pelos professores da rede municipal de União da Vitória/PR?

Para responder a esta questão, este estudo, de caráter exploratório e qualitativo, buscou compreender o fenômeno investigado, com o objetivo de investigar a contribuição da política do Pacto Nacional pela Alfabetização na Idade Certa (PNAIC) para a formação continuada de professores alfabetizadores do município de União da Vitória/PR.

Considerou-se que a criação do PNAIC contribui significativamente para a complementação da formação dos professores, oferecendo novas propostas metodológicas, grupos de estudos, reuniões com pesquisas e debates. Estes métodos possibilitam e incentivam o surgimento de novas ideias, para se trabalhar em sala de aula, como: as dinâmicas, os jogos e as brincadeiras lúdicas, criando um ambiente propício para se obter um maior rendimento no desenvolvimento do aluno e consequentemente em seu aprendizado contribuindo para a sua alfabetização.

\section{REFERENCIAL TEÓRICO}

\subsection{Pacto Nacional pela Alfabetização na Idade Certa e o ambiente alfabetizador}

Atualmente há uma crescente reflexão sobre o papel do professor na sociedade pós moderna, com um novo modelo para sua formação. O saber sobre o ensino não é mais visto através da lógica da racionalidade técnica, passando a ser construído e assumido a partir de uma prática crítico-reflexiva (FREITAS; VILLANI, 2002).

Os professores são atores competentes, sujeitos ativos, deveremos admitir que a prática deles não é somente um espaço de aplicação de saberes provenientes da teoria, mas também um espaço de produção de saberes específicos provenientes dessa mesma prática (TARDIF, 2012).

Entre os professores formadores do ensino superior e do ensino básico, destaca-se o professor alfabetizador que incorpora a sua experiência prática às aulas, visando um processo de aprendizagem através do qual retraduzem sua formação e adaptam a sua profissão (TARDIF, 2012; LUCIO, 2013).

Neste cenário profissional, uma realidade se apresenta: o país necessita avançar significativamente no tocante aos índices de melhoria no desempenho dos nossos alunos nas 


\section{Revista}

\section{Triângulo}

áreas de leitura/escrita e matemática. Para arrefecer as tensões, o governo federal criou em julho de 2012 o Pacto Nacional pela Alfabetização na Idade Certa (PNAIC). Instituído pela portaria $\mathrm{n}^{\mathrm{o}} 867$ de 4 de julho de 2012 e celebrado pelas três esferas governamentais para investir na formação docente de profissionais que atuam nos três primeiros anos do Ensino Fundamental, tem a finalidade precípua de alfabetizar os alunos até no máximo os oito anos de idade, ou seja, ao final do $3^{\circ}$ ano do Ensino Fundamental (BRASIL, 2012).

O PNAIC é constituído por um conjunto integrado de ações, materiais e referências curriculares e pedagógicas disponibilizados pelo MEC, tendo como eixo principal a formação continuada de professores alfabetizadores (BRASIL, 2012).

O PNAIC assegura aos seus participantes, por meio de um de seus eixos estruturantes (materiais didáticos e pedagógicos), composto por conjuntos de materiais específicos para alfabetização, a apresentação de uma ampla e diversa reflexão teórica sobre a alfabetização e os caminhos para utilização em sala de aula dos jogos pedagógicos, acervos do Programa Biblioteca em sua Casa (PNBE) e do Programa Nacional do Livro Didático (PNLD). Igualmente proporciona aos docentes, reflexões do agir pedagógico sobre o trabalho com o sistema de escrita. Também oferece aos participantes, fundamentações e reflexões sobre os conceitos de alfabetização e letramento, currículo, rotina, planejamento, ludicidade, literatura, biblioteca escolar e o ensino da língua portuguesa na alfabetização (LUCIO, 2013).

Conforme o entendimento de Souza (2014), a criança é alfabetizada quando compreende o funcionamento da escrita, domina as correspondências entre grafema-fonema, lê, escreve e compreende textos escritos. Contudo, a partir desta perspectiva, é preciso disponibilizar o acesso aos instrumentos pedagógicos e é importante que o professor, figura central neste processo, saiba utilizá-los com a realização de intervenções pedagógicas em sua plenitude.

O PNAIC considera que é preciso assegurar a formação continuada para que o trabalho docente nesta importante fase de desenvolvimento e aprendizagem dos alunos seja desempenhado com competência e entusiasmo. De outra forma seus organizadores consideram valorizar o papel do professor neste processo, visto ser ele um importante profissional no desenvolvimento de pessoas e do conhecimento do mundo, pois é ele quem favorece a aprendizagem e "organiza um determinado conhecimento dispondo de uma certa maneira de propiciar boas condições de aprendizagem" (BRASIL, 2012, s/p.).

\begin{tabular}{l|l|l|l|l|l|l|} 
(C) Rev. Triang. & Uberaba, MG & v.10 & n.2 & p.190-207 & Jul./Dez. 2017 & ISSN 2175-1609
\end{tabular}




\section{Revista}

\section{Triângulo}

A formação continuada agrega ao processo do exercício profissional docente a melhoria das práticas pedagógicas tanto em seu trabalho como no cotidiano escolar. Além disso, a formação incluiu também a ideia de aprendizagem constante no sentido de provocar inovação na construção de novos conhecimentos que darão suporte teórico ao trabalho docente (DASSOLER; LIMA, 2012).

Evidencia-se que o professor necessita de novos sistemas de trabalho e de novas aprendizagens para exercer sua profissão qualificadamente sendo que as aprendizagens adquiridas se associam às instituições educativas, pois se constituem em núcleos em que se trabalha um conjunto de pessoas. Neste tocante, a formação é autêntica quando contribuiu para o desenvolvimento profissional no campo de trabalho e nas aprendizagens profissionais (IMBERNÓN, 2010).

\section{MATERIAIS E MÉTODOS}

A pesquisa de campo contou com todos os professores participantes do programa PNAIC nos anos de 2015/2016, atuantes no município de União da Vitória - PR, totalizando 15 sujeitos respondentes.

Para a obtenção dos dados foi elaborado um questionário semiestruturado, no qual as questões fechadas foram elaboradas conforme o método desenvolvido por Likert (1932), para mensurar atitudes no contexto das ciências comportamentais. A escala de verificação de Likert consiste em tomar um construto e desenvolver um conjunto de afirmações relacionadas à sua definição, para as quais os respondentes emitirão seu grau de concordância (SILVA JÚNIOR; COSTA, 2014).

O questionário foi enviado aos respondentes por meio da plataforma online "Google docs." Após um período de um mês com reenvio do questionário, obtive-se 8 participações na pesquisa.

O Quadro 1, demostra a escala de Likert elaborada para este estudo, no qual cada resposta é indicada por um número da escala, representando a opinião do respondente.

Quadro 1- Modelo da Escala de Likert elaborada para construção do instrumento de coleta dos dados.

\begin{tabular}{|c|c|c|c|c|c|c|c|}
\hline \multicolumn{7}{|c|}{ Escala de Likert } \\
\hline Discorda & Discorda & \multicolumn{3}{c|}{ Sem Opinião } & \multicolumn{2}{c|}{ Concordo } & \multicolumn{2}{c|}{ Concordo } \\
\hline \hline C Rev. Triang. & \multicolumn{1}{|c|}{ Uberaba, MG } & v.10 & n.2 & p.190-207 & Jul./Dez. 2017 & ISSN 2175-1609 \\
\hline
\end{tabular}




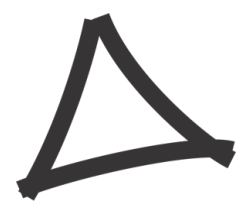

\section{Revista}

\section{Triângulo}

\begin{tabular}{|c|c|c|c|c|}
\hline fortemente & & & & fortemente \\
\hline 1 & 2 & 3 & 4 & 5 \\
\hline
\end{tabular}

Fonte: Adaptado de Silva Júnior e Costa (2014).

O questionário foi estruturado pelas pesquisadoras e constou de 8 perguntas fechadas e 1 pergunta aberta. As perguntas foram direcionadas para que se pudessem encontrar índices na contribuição da alfabetização dos estudantes dos sistemas públicos de ensino, visando analisar se o referido Programa está contribuindo para que os estudantes estejam alfabetizados, até o final do $3^{\circ}$ ano do ensino fundamental.

Para fonte da estrutura das perguntas do instrumento de coleta dos dados, o conteúdo foi fundamentado nos objetivos das ações do PNAIC, conforme consta no artigo $5 .^{\circ}$ portaria $\mathrm{n}^{\circ} 867$, de 4 de julho de 2012, sendo ajustadas conforme o método de Likert (1932). Seguem os seguintes objetivos das ações do PNAIC:

I - garantir que todos os estudantes dos sistemas públicos de ensino estejam alfabetizados, em Língua Portuguesa e em Matemática, até o final do $3^{\circ}$ ano do ensino fundamental;

II - reduzir a distorção idade-série na Educação Básica;

III - melhorar o Índice de Desenvolvimento da Educação Básica (IDEB);

IV - contribuir para o aperfeiçoamento da formação dos professores alfabetizadores;

V - construir propostas para a definição dos direitos de aprendizagem e desenvolvimento das crianças nos três primeiros anos do ensino fundamental. (BRASIL, 2012).

A sistematização e análise dos dados coletados foram divididas em duas etapas. $\mathrm{Na}$ primeira etapa foram sistematizadas as 8 perguntas objetivas do questionário (aplicado aos professores), organizado segundo os objetivos do PNAIC. Na segunda etapa realizou-se a análise e a interpretação da resposta, inter-relacionando com a contribuição do PNAIC nas atividades desenvolvidas em sala de aula com os alunos dos anos iniciais de acordo com a técnica de análise de conteúdo (BARDIN, 2011).

\section{ANÁLISE DOS DADOS E RESULTADOS}




\section{Revista}

\section{Triângulo}

Para a categorização das respostas, os professores foram codificados com a letra "P", seguida de um número que representa cada professor entrevistado, assim, o primeiro professor recebeu a codificação "P1", o segundo recebeu a codificação "P2" e assim sucessivamente.

As perguntas foram codificadas aos professores pela letra "E" seguida de um número que corresponde à sequência. O Quadro 2 apresenta a estrutura das questões do instrumento de coleta dos dados da pesquisa: 


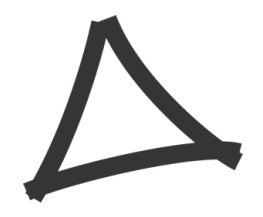

Revista

Triângulo

Quadro 2 - Organização das questões do instrumento de coleta dos dados

\begin{tabular}{|c|c|}
\hline $\begin{array}{l}\text { Código da } \\
\text { questão }\end{array}$ & QUESTÃO \\
\hline E01: & $\begin{array}{l}\text { Com relação a sua formação acadêmica, assinale a alternativa que se enquadra em seu } \\
\text { currículo. (Formação). }\end{array}$ \\
\hline E02: & $\begin{array}{l}\text { Em que ano você iniciou suas atividades no Projeto PNAIC? (Tempo de participação no } \\
\text { projeto). }\end{array}$ \\
\hline$E 03$ & $\begin{array}{l}\text { A partir do emprego do projeto do PNAIC os seus alunos, demonstraram melhor } \\
\text { entendimento nas atividades propostas por você e é considerável o aumento na } \\
\text { aprendizagem, fato que contribui para que estejam alfabetizados até o final do } 3^{\circ} \text { ano do } \\
\text { Ensino Fundamental. (Objetivo do PNAIC 01). }\end{array}$ \\
\hline E04 & $\begin{array}{l}\text { De acordo com o seu tempo de participação no PNAIC e seu desempenho docente, seus } \\
\text { alunos estarão plenamente alfabetizados em Língua Portuguesa e Matemática ao final do } \\
3^{\circ} \text { ano do Ensino Fundamental. Está afirmação eu: (Objetivo do PNAIC 01). }\end{array}$ \\
\hline E05 & $\begin{array}{l}\text { Com base nas orientações do projeto, você constata que a aprendizagem dos teus alunos, } \\
\text { está melhorando com aproveitamento do conteúdo, sendo que em sua turma não há a } \\
\text { distorção idade-série. (Objetivo do PNAIC } 02 \text { E 03). }\end{array}$ \\
\hline E06 & $\begin{array}{l}\text { Sua convivência com alunos e professores e a equipe pedagógica, dentro do ambiente } \\
\text { escolar, associado ao seu envolvimento como professor participante do PNAIC, está lhe } \\
\text { despertando um maior interesse pela docencia e sendo que, este contribui para seu } \\
\text { aperfeiçoamento como professor alfabetizador. (Objetivo do PNAIC 04). }\end{array}$ \\
\hline E07 & $\begin{array}{l}\text { O projeto PNAIC proporciona um melhor entendimento sobre o aprendizado do aluno, } \\
\text { uma vez que a metodologia utilizada pelo professor em sala de aula é aperfeiçoada, } \\
\text { oportunizando ao professor aprender diferentes técnicas de ensino, aumentando a } \\
\text { eficiência e rendimento das aulas. (Objetivo do PNAIC 04). }\end{array}$ \\
\hline E08: & $\begin{array}{l}\text { O Projeto PNAIC está lhe proporcionando experiências didáticas que possibilitam a } \\
\text { construção de novas alternativas pedagógicas que asseguram os direitos de aprendizagem } \\
\text { e desenvolvimento das crianças. (Objetivo do PNAIC 05). }\end{array}$ \\
\hline E09: & $\begin{array}{l}\text { Esta última pergunta o professor responde como se fosse uma questão geral. Onde tem por } \\
\text { finalidade englobar todos os objetivos da pesquisa. } \\
\text { Ofereça um relato sobre a sua percepção do Projeto PNAIC e a contribuição do mesmo } \\
\text { para a sua formação continuada. Se possivel dê um exemplo. }\end{array}$ \\
\hline
\end{tabular}

Fonte: Dados das pesquisadoras (2016).

A questão 1 versou sobre a formação acadêmica dos entrevistados, os dados demonstraram que apenas $25 \%$ dos professores respondentes apresentam uma graduação na área da Educação, 62,5\% dos professores responderam conter uma especialização na área da Educação e 12,5\% possuem mais de uma especialização na área da Educação. Os dados apontam um indicador positivo para o sistema educacional do município de União da Vitória/PR todos os professores respondentes tem formação na área específica de atuação. 


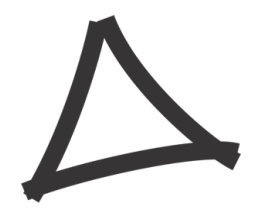

Revista

\section{Triângulo}

A questão 2 ainda se refere ao perfil dos professores e coletou dados referentes ao tempo de participação dos respondentes no Projeto PNAIC. Onde, 37,5\% dos professores responderam que estão participando entre o espaço temporal de 1 a 2 anos, 50\% responderam estarem participando há 3 anos do programa, e 12,5\% dos entrevistados responderam estar participando mais de 4 anos do projeto. Assim se constata que não há professores principiantes participando do PNAIC na amostra pesquisada.

A questão 3 apresentou a seguinte afirmação: "A partir do emprego do projeto do PNAIC os seus alunos, demonstraram melhor entendimento nas atividades propostas por você e é considerável o aumento na aprendizagem, fato que contribui para que estejam alfabetizados até o final do $3^{\circ}$ ano do Ensino Fundamental (Objetivo do PNAIC 01). As respostas foram dadas conforme a escala de Likert e são apresentadas no (Gráfico 3). Constata-se que: $0 \%$ "Discordam fortemente", 12,5\% "Discordam", 25\% "Sem opinião", 25\% "Concordam" e 37,5\% "Concordam fortemente".

Gráfico 3: Grau de concordância dos professores respondentes sobre a contribuição do PNAIC. Para a aprendizagem dos alunos e contribuição para estarem alfabetizadas até o final do $3 .^{\circ}$ ano do Ensino Fundamental.

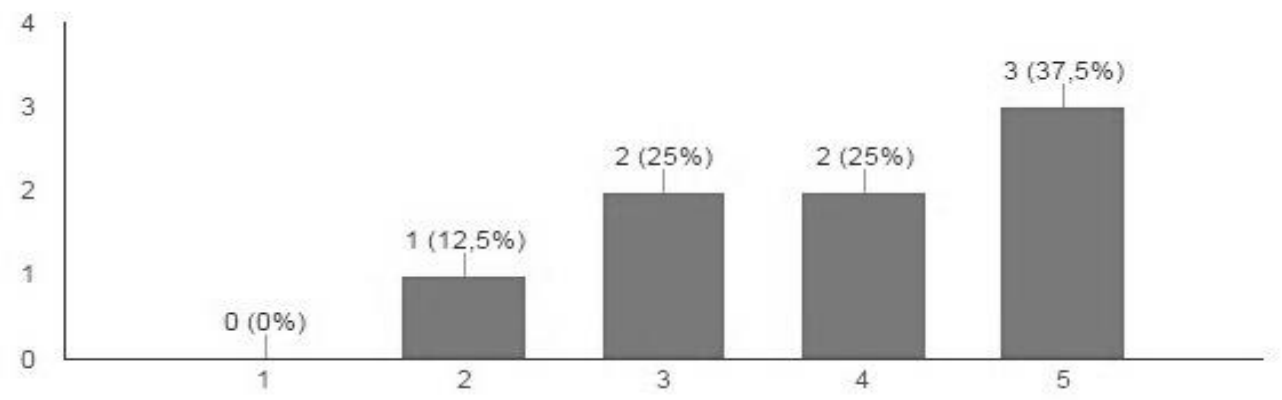

Fonte: Dados das pesquisadoras (2016).

A questão de número 4 tem a seguinte assertiva: "De acordo com o seu tempo de participação no PNAIC e seu desempenho docente, seus alunos estarão plenamente alfabetizados em Língua Portuguesa e Matemática ao final do $3^{\circ}$ ano do Ensino Fundamental?".

A partir dos dados sistematizados no (Gráfico 4), observa-se que nenhum dos professores respondentes optou pelas respostas "Discordar" ou "Discordar fortemente", 25\% responderam estarem "Sem opinião", 50\% "Concordam", 25\% "Concordam fortemente". 


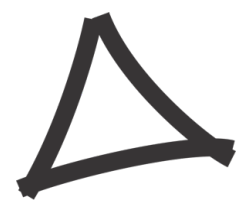

\section{Revista}

\section{Triângulo}

Gráfico 4: Grau de concordância com a assertiva sobre se o respondente relaciona o seu tempo de participação no Projeto PNAIC com o fato dos seus alunos se encontrarem alfabetizados até o final do $3^{\circ}$ ano do Ensino Fundamental.

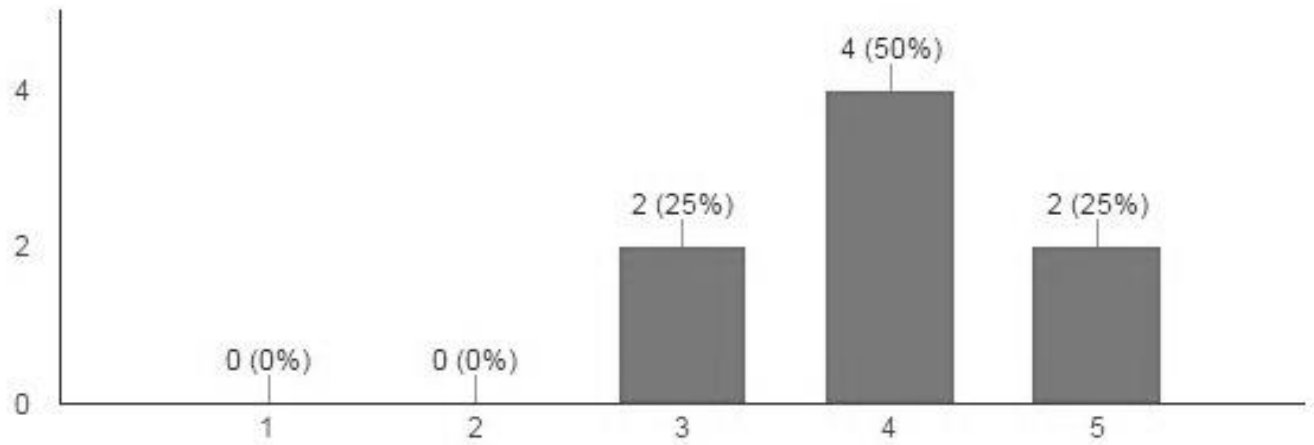

Fonte: Dados das pesquisadoras (2016)

A questão 5 apresentou a seguinte afirmação aos professores respondentes: "Com base nas orientações do projeto, você constata que a aprendizagem dos teus alunos, está melhorando com aproveitamento do conteúdo, sendo que em sua turma não há a distorção idade-série." Os dados apontam que nesta questão $0 \%$ dos entrevistados "Discordam fortemente", $0 \%$ "Discordam", 25\% "Sem opinião", 50\% "Concordam" e 25\% "Concordam fortemente" (Gráfico 5).

Gráfico 5: Grau de concordância dos professores respondentes sobre a constatação da melhoria da aprendizagem dos alunos e melhoria do aproveitamento do conteúdo e da diminuição da distorção idade/série, a partir da participação no PNAIC.

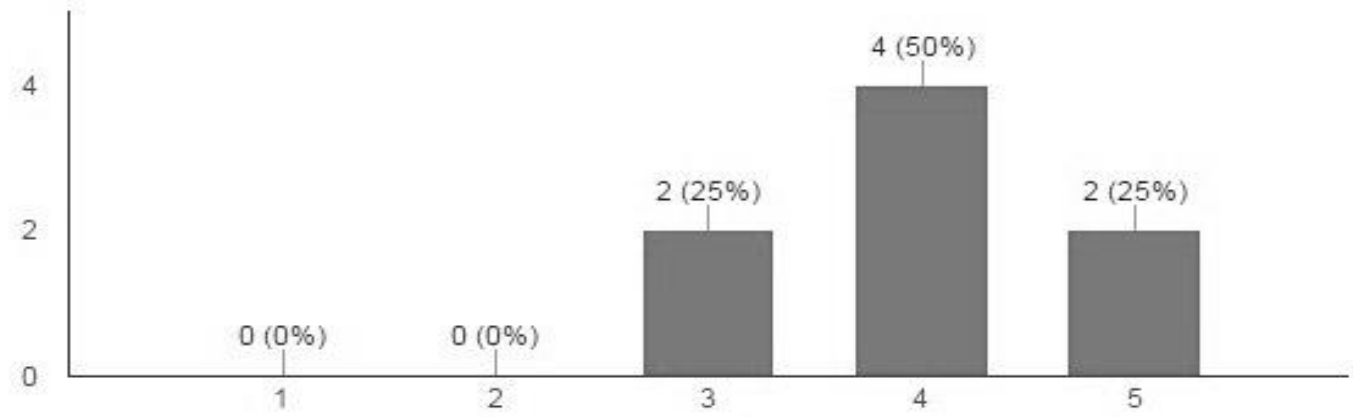

Fonte: Dados das pesquisadoras (2016) 


\section{Revista}

\section{Triângulo}

A questão 6 apresentou a seguinte afirmação aos professores respondentes: "Sua convivência com alunos e professores e a equipe pedagógica, dentro do ambiente escolar, associado ao seu envolvimento como professor participante do PNAIC, está lhe despertando um maior interesse pela docência e sendo que, este contribui para seu aperfeiçoamento como professor alfabetizador".

A partir dos dados apresentados no (Gráfico 6), pode-se notar que esta afirmação gerou os seguintes graus de concordância dos professores respondentes: $0 \%$ "Discorda fortemente", $0 \%$ "Discordam", 25\% "Sem opinião", 12,5\% "Concordam" e 62,5\% "Concordam fortemente".

Gráfico 6: Grau de concordância dos respondentes sobre o fato de que a convivência com alunos, professores e a equipe pedagógica, dentro do ambiente escolar, associado ao seu envolvimento como professor participante do PNAIC, está despertando um maior interesse pela docência.

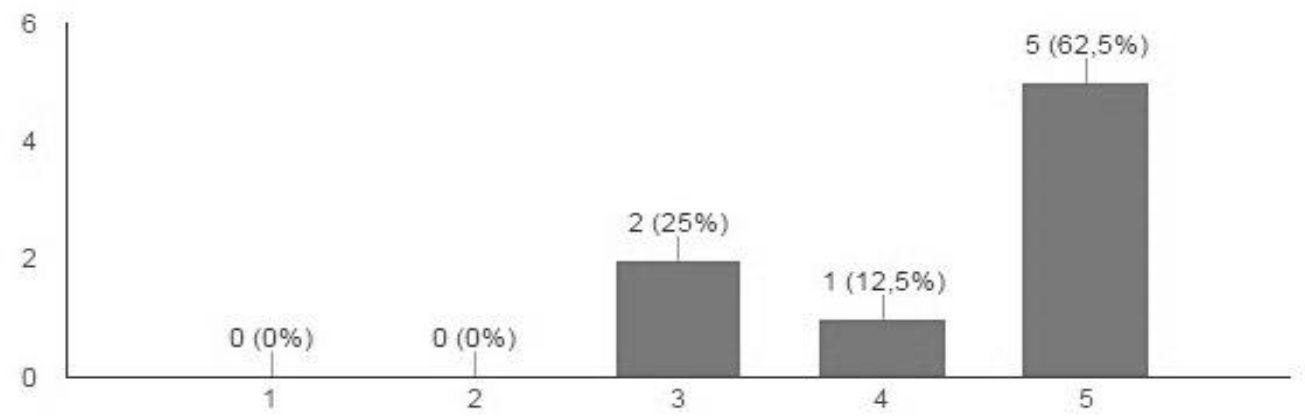

Fonte: Dados das pesquisadoras (2016).

Na questão de n. ${ }^{\circ} 7$ o objetivo foi questionar o grau de concordância dos respondentes sobre diante da seguinte afirmação: "O projeto PNAIC proporciona um melhor entendimento sobre o aprendizado do aluno, uma vez que a metodologia utilizada pelo professor em sala de aula é aperfeiçoada, oportunizando ao professor aprender diferentes técnicas de ensino, aumentando a eficiência e rendimento das aulas? ".

Os dados coletados e apresentados no (Gráfico 7) revelam que o grau de concordância dos respondentes sobre a assertiva $n^{\circ} 7$ é a seguinte: $0 \%$ "Discordam fortemente", 12,5\% "Discordam”, 12,5\% "Sem opinião", 25\% “Concordam” e 50\% "Concordam fortemente".

Gráfico 7: Grau de concordância dos respondentes sobre o fato de o PNAIC proporciona um melhor entendimento sobre o aprendizado do aluno, uma vez que a metodologia utilizada pelo professor em sala de 


\section{Revista}

\section{Triângulo}

aula é aperfeiçoada, com aprendizagens diferentes de técnicas de ensino, aumentando a eficiência e rendimento das aulas.

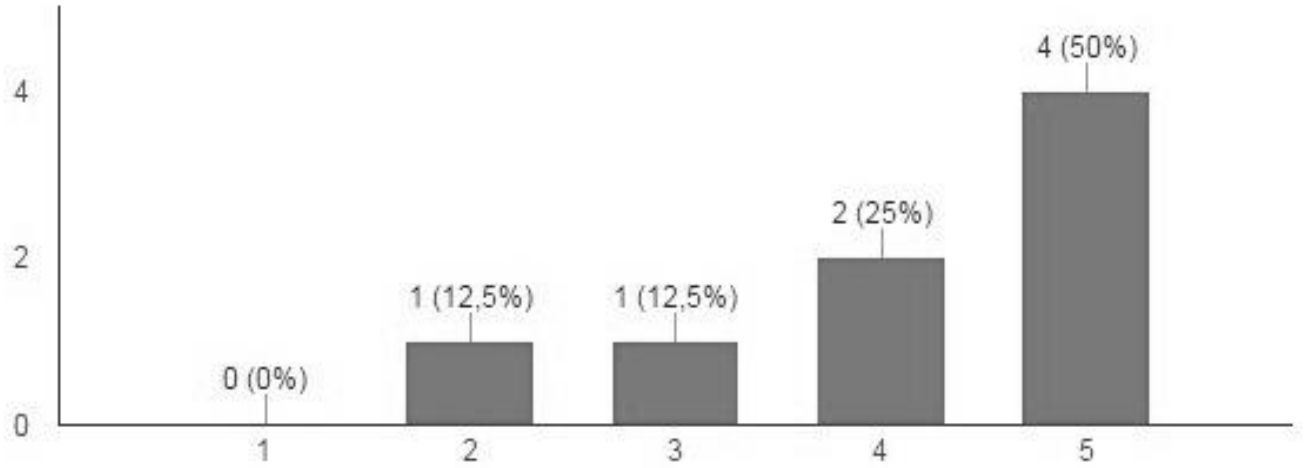

Fonte: Dados das pesquisadoras (2016).

A questão de número 8, sobre o grau de concordância dos respondentes, apresentou a seguinte afirmação: "O Projeto PNAIC está lhe proporcionando experiências didáticas que possibilitam a construção de novas alternativas pedagógicas que asseguram os direitos de aprendizagem e desenvolvimento das crianças." O panorama desenhado pelos respondentes e observado no (Gráfico 8) aponta que 0\% "Discordam fortemente", 0\% "Discordam", 25\% “Sem opinião", 12,5\% "Concordam" e 62,5\% "Concordam fortemente".

Gráfico 8: Grau de concordância dos respondentes sobre o fato de o PNAIC está lhe proporcionando experiências didáticas que possibilitam a construção de novas alternativas pedagógicas que asseguram os direitos de aprendizagem e desenvolvimento das criança

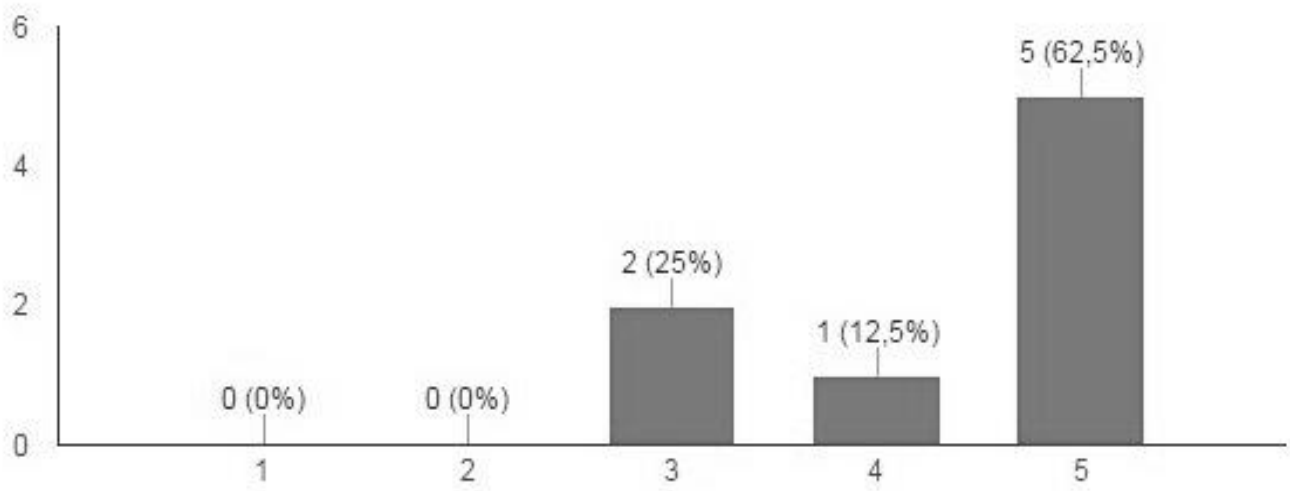

Fonte: Dados das pesquisadoras (2016). 


\section{$\Delta$}

\section{Revista}

\section{Triângulo}

A questão $\mathrm{n}^{\circ} 9$ foi estruturada de forma aberta aos professores respondentes e solicitou: "Ofereça um relato sobre a sua percepção do Projeto PNAIC e a contribuição do mesmo para a sua formação continuada. Se possível de um exemplo."

Para maior entendimento, as respostas foram agrupadas e categorizadas conforme os objetivos do PNAIC e são apresentadas a partir destes, sendo que se desenharam da seguinte forma (é importante ressaltar que em todas as tabelas apresentadas a seguir, uma resposta contém mais de uma categoria, portanto o total da frequência é maior do que o número de respondentes):

Objetivo I - "Garantir que todos os estudantes dos sistemas públicos de ensino estejam alfabetizados, em Língua Portuguesa e em Matemática, até o final do $3^{\circ}$ ano do Ensino Fundamental".

A resposta à esta questão deste objetivo foi apontada por $10 \%$ dos entrevistados. A percepção e análise do respondente $\mathrm{P} 1$ é significativa ao afirmar que: "Os cursos do PNAIC voltados para os professores alfabetizadores apresentam métodos e estratégias diferenciadas para que os alunos adquiram o código linguístico, não somente na leitura escrita e alfabetização matemática, mas também como cidadão íntegros, críticos e reflexivos, capazes de participar ativamente frente às diversas realidades".

Objetivo III - Melhorar o Índice de Desenvolvimento da Educação Básica (IDEB). No conteúdo de $10 \%$ dos professores respondentes se encontra este objetivo. A resposta de: P5 é relevante no contexto do estudo quando afirma que: “... percebi que os alunos aprenderam com mais facilidade, e o interesse pelo assunto trabalhado com o uso da metodologia diferenciada atraiu a atenção de todos os alunos...".

Objetivo IV - Contribuir para o aperfeiçoamento da formação dos professores alfabetizadores. O conteúdo deste objetivo foi apontado por $50 \%$ dos professores respondentes. O Quadro 3 ilustra os depoimentos mais significativos:

Quadro 9 - Respostas dos professores respondentes referente à questão aberta 9, de acordo com o objetivo IV do PNAIC

\begin{tabular}{|l|l|}
\hline Respondente & \multicolumn{1}{|c|}{ DEPOIMENTO } \\
\hline P2 & $\begin{array}{l}\text { "A participação no PNAIC oportuniza troca de experiências com os professores da } \\
\text { rede municipal, melhorando o desempenho profissional em sala de aula. Ex. troca de } \\
\text { atividades. Jogos, novas ideias para solução de dificuldades de aprendizagem. } \\
\text { Contribui muito para a formação profissional". }\end{array}$ \\
\hline
\end{tabular}




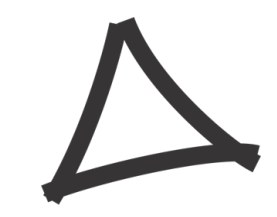

Revista

Triângulo

\begin{tabular}{|l|l|}
\hline P3 & $\begin{array}{l}\text { "O PNAIC é valioso enquanto o momento de debate entre educadores e a troca de } \\
\text { experiência... Além disso no PNAIC é uma formação importante que todos os } \\
\text { alfabetizadores devem participar". }\end{array}$ \\
\hline P5 & $\begin{array}{l}\text { "Apliquei as Sequências Didáticas Interdisciplinares sugeridas pelo Projeto PNAIC, } \\
\text { trabalhando diversos temas, como: Meios de Transportes, Higiene Bucal, entre } \\
\text { outros... Percebendo o quanto o Projeto contribui em minhas aulas e com o resultado } \\
\text { que tive com os alunos, pretendendo este ano continuar fazendo o PNAIC". }\end{array}$ \\
\hline P6 & $\begin{array}{l}\text { "A possibilidade de participar de um Programa como o PNAIC, é única, tendo em } \\
\text { vista as sugestões de atividades e as trocas de ideias que acontecem durante os } \\
\text { encontros. Com certeza, esta oportunidade, muda nossa postura como professores...". }\end{array}$ \\
\hline P7 & $\begin{array}{l}\text { "O Projeto é muito bom e os materiais excelentes, a interação com outros professores } \\
\text { alfabetizadores enriquece muito a prática...". }\end{array}$ \\
\hline
\end{tabular}

Fonte: Dados das pesquisadoras (2016).

Objetivo V - Construir propostas para a definição dos direitos de aprendizagem e desenvolvimento das crianças nos três primeiros anos do ensino fundamental, apontado por $30 \%$ dos professores respondentes, Quadro 4.

Quadro 10 - Respostas dos professores respondentes referente a questão aberta 9, de acordo com o objetivo V do PNAIC

\begin{tabular}{|l|l|}
\hline Respondente & \multicolumn{1}{c|}{ DEPOIMENTO } \\
\hline P4 & $\begin{array}{l}\text { "O PNAIC abriu novas possibilidades de atividades em sala de aula, bem como, uma } \\
\text { nova visão de ensino-aprendizagem". }\end{array}$ \\
\hline P5 & $\begin{array}{l}\text { "... Foi trabalhado contemplando todas as disciplinas, utilizei os livros sugeridos no } \\
\text { projeto, e também nos jogos pedagógicos que enriquecem muito minha aula. Foi } \\
\text { gratificante o resultado...". }\end{array}$ \\
\hline P6 & $\begin{array}{l}\text { "... ficamos mais perspicazes e atentos ao que realmente é significativo para os alunos. } \\
\text { e interessantes. Dessa foram o aluno aprende brincando". }\end{array}$ \\
\hline
\end{tabular}

Fonte: Dados das pesquisadoras (2016).

A seguir, os dados coletados serão analisados e interpretados. Sendo realizada a discussão dos resultados da pesquisa. 


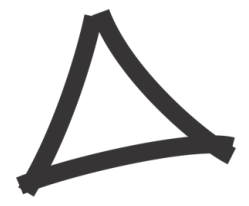

\section{Revista}

\section{Triângulo}

A partir dos dados das 8 questões com respostas fechadas e estruturadas conforme a escala Lickert sistematizados e apresentados, algumas inferências podem ser assim elencadas a apartir dos objetivos do estudo:

$\mathrm{Na}$ questão 1 analisa-se o perfil dos professores respondentes constatando que todos possuem uma graduação na área da educação, destacando-se os que apresentam mais de um curso de pós- graduação. Com isto percebe-se o interrese pela complementação e atualização da formação pedagógica e pela melhoria de sua prática docente.

A pesquisa revela que o tempo de participação dos professores no PNAIC, é superior a 6 meses, chegando a mais de 4 anos em alguns casos, como é possível observar nas respostas da Questão 2. Isto, demonstra o impacto positivo que o PNAIC apresenta no cotidiano do ambiente escolar, auxiliando na prática pedagógica do professor obtendo-se melhores resultados no desempenho dos alunos.

$\mathrm{Na}$ questão 3 é possível observar que mais de $60 \%$ dos professores respondentes notaram melhora no desempenho na alfabetização dos alunos, pois estes, demonstraram maior entendimento do conteúdo, obtendo um melhor aproveitamento dos conteúdos trabalhados. $25 \%$ dos professores respondentes não observaram mudanças significativas no desempenho dos seus alunos com a metodologia proposta pelo PNAIC. Este resultado reflete o encontrado na pergunta número 4 , em que: $25 \%$ dos professores respondentes revelam não ter uma opinião formada sobre os resultados que irão obter com as práticas do PNAIC e 75\% acreditam que seus alunos estaram plenamente alfabetizados em Língua Portuguesa e Matemática até o final do $3^{\circ}$ ano do ensino fundamental, reforçando assim a percepção de um melhor entendimento dos alunos sobre o conteúdo frente às metodológias utilizadas.

A distorção idade série é um problema que afeta o desenvolvimento dos alunos, causando problemas na aprendizagem. Isto acontece devido a má interpretação e entendimento do conteúdo ministrado em sala de aula. Observa-se na Questão 05 , que 75\% dos professores respondentes acreditam minimizar este problema devido ao melhor aproveitamento e entendimento do conteúdo pelos alunos, adjunto às orientações do PNAIC em suas aulas.

A formação de professores não deve ser dominada apenas por conteúdos e lógicas disciplinares, mas também por experiências profissionais (TARDIF, 2013). Na Questão 6 é possível observar que a interação e convivência com outros professores têm influencia 


\section{$\Delta$}

\section{Revista}

\section{Triângulo}

positiva em suas práticas pedagógicas. $75 \%$ dos professores respondentes afirmam ter mais interesse pela prática pedagógica, após os encontros e reuniões com os grupos de estudos e com a equipe pedagógica. Com isto, percebe-se a busca dos professores pela troca de experiencias com outros professores que cada vez mais contribuem para sua capacitação profissional. 25\% afirmaram não possuírem opinião sobre o tema.

Na questão 7 é possível observar que o PNAIC proporcionou um melhor entendimento sobre o aprendizado dos alunos, em que: $75 \%$ dos professores respondentes afirmam que diferentes técnicas de ensino surtem melhores resultados aumentando o rendimento das aulas. $25 \%$ afirmaram não possuírem opinião sobre o tema. Tedesco (2015) encontrou resultados semelhantes ao pesquisar sobre experiências integradoras de políticas educacionais - PNAIC e PROUCA em que foi possível perceber o comprometimento e a preocupação dos docentes com o ato de ensinar e aprender de maneira reflexiva, inovadora e qualitativa pela inserção das tecnologias digitais e o novo olhar para a aprendizagem de alunos no ciclo de alfabetização.

$\mathrm{Na}$ questão 8 foi possível perceber que $75 \%$ do professores respondentes apontaram que as práticas didáticas propostas pelo PNAIC oportunizam ao aluno a associação dos conteúdos aprendidos com os novos conteúdos a serem trabalhados, dando sequência no aprendizado. 25\% afirmaram não possuír opinião sobre o tema. Para Imbernón (2010) faz-se possível trazer novas questões práticas e buscar compreendê-las sob o enfoque da teoria, o que permite articular novos saberes na construção da docência.

$\mathrm{Na}$ Questão 9, é possível perceber a satisfação dos professores respondentes com os resultados encontrados através da participação no PNAIC. O projeto contribuiu para o aperfeiçoamento dos professores alfabetizadores, possibilitando somarem novos conceitos e metodologias em sua prática docente. Nesta questão, também, foram apontados como pontos positivos a melhora do IDEB e a alfabetização dos alunos até o final do $3^{\circ}$ ano do ensino fundamental. 


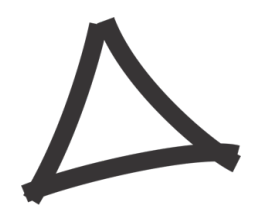

Revista

Triângulo

\section{CONSIDERAÇÕES FINAIS}

O PNAIC contribui para a formação dos professores alfabetizadores, trazendo novas metodologias que auxiliam no desenvolvimento educacional dos alunos nos três primeiros anos do ensino fundamental.

Dessa maneira, entende-se que a formação do professor não se acaba na conclusão do seu curso de graduação, mas se consolida continuamente na sala de aula, onde dúvidas e conflitos aparecem a cada dia. A Formação Continuada de professores alfabetizadores contribui para reflexão e tomada de decisões para melhoria da prática pedagógica utilizada no ambiente da sala de aula.

Sendo assim, a alfabetização dita que a dimensão do letramento em sala de aula necessita de situações que abordem de forma reflexiva as diferentes linguagens. Considera-se que a educação não deve ser usada de modo que o ensino seja apenas uma passagem de informações, mas sim, um processo interativo, colaborativo e de diálogo, que possibilite o enriquecimento do aprendizado, criando um ambiente favorável à formação do pensamento crítico, criativo e cooperativo, no qual a metodologia favorece o trabalho pedagógico para que seja realmente possível a alfabetização até o final do $3^{\circ}$ ano do ensino fundamental.

\section{REFERÊNCIAS}

BARDIN, L. Análise de conteúdo. Lisboa: Edições 70.

Brasil. Ministério da educação. Gabinete do ministro. Portaria ${ }^{\circ} 867$ de 4 de julho de 2012 . Institui o Pacto pela Educação na Idade Certa e as ações do Pacto e define suas diretrizes gerais. Disponível em: http://pacto.mec.gov.br/images/pdf/2016/Portarias/PORTARIA_N_867_DE_4_DE_JULHO_ DE_2012.pdf. Acesso em 10 de maio de 2016.

BRASIL. Secretaria de Educação Básica. Diretoria de Apoio à Gestão Educacional. Pacto nacional pela alfabetização na idade certa: formação do professor alfabetizador: caderno de apresentação. Ministério da Educação, Secretaria de Educação Básica, Diretoria de Apoio à Gestão Educacional. Brasília: MEC, SEB, 2012. Disponível em: http://pacto.mec.gov.br/images/pdf/Formacao/Apresentacao\%20MIOLO.pdf Acesso em 18 maio 2016.

DASSOLER, O. B; LIMA, D. M. S. A formação e a profissionalização docente: características, ousadas e saberes. IX ANPED SUL. Seminário de pesquisa em Educação da 


\section{$\Delta$}

\section{Revista}

\section{Triângulo}

região

do

Sul.

2012.

Disponível

em:

http://www.ucs.br/etc/conferencias/index.php/anpedsul/9anpedsul/paper/

viewFile/3171/522. Acesso em 4 maio 2016.

IMBERNÓN, F. Formação docente e profissional: formar-se para a mudança e a incerteza. 8. ed. São Paulo. 2010.

FREITAS, D; VILLANI, A. Formação de Professores de Ciências: Um desafio sem limites. Revista Investigações em Ensino de Ciências, v.7, n. 3, p. 215-230, 2002. Disponível em: http://www.if.ufrgs.br/ienci/artigos/Artigo_ID90/v7_n3_a2002.pdf Acesso em 25 maio 2016.

LIKERT, R. A technique for the measurement of attitudes. Archives in Psychology, 140, p. 1-55,1932. Disponível em https://legacy.voteview.com/pdf/Likert_1932.pdf Acesso em 5 maio 2016.

LIMA, P. G; BARRETO, E. M. G; LIMA, R. R. Formação Docente: Uma Reflexão Necessária. Revista de Educação Educare et Educare. Campus de Cascavel. Ed. Edunioeste. Vol. 2 n ${ }^{0} 4$ jul./dez. 2007. p. 91-101. Disponível em: file://C:/Users/User/Downloads/1657-5850-1-PB.pdf Acesso em 10 jun. 2016.

LUCIO, E. O. O Pacto Nacional Pelos Direitos do Professor Alfabetizador: por uma política de responsabilidade e uma docência de responsividade. Revista Práticas de Linguagem. v. 3, n. 1, jan./ jun. 2013. p. 111-118. Disponível em: http://www.ufjf.br/praticasdelinguagem/files/2013/07/112-118-Fale-para-o-professor.pdf Acesso em 10 jun. 2016.

SILVA JÚNIOR, S. D; COSTA, F. J; Mensuração e Escalas de Verificação: uma Análise Comparativa das Escalas de Likert e Phrase Completion. PMKT - Revista Brasileira de Pesquisa de Marketing, Opinião e Mídia. Publicado por: ABEP - Associação Brasileira de Empresa de Pesquisa. Disponível em: www.revistapmkt.com.br Acesso em 20 jun. 2016.

SOUZA, E. E. P. A formação no Pacto Nacional pela Alfabetização na Idade Certa (PNAIC). In: X ANPED SUL, Florianópolis. Anais. Outubro de 2014, p. 1-18. Disponível em: http://xanpedsul.faed.udesc.br/arq pdf/95-0.pdf Acesso em 15 jun. 2016.

TARDIF, M. Saberes docentes e formação profissional. 13. ed. Petrópolis: Vozes, 2012.

TEDESCO, S. Formação continuada de professores: experiências integradoras de políticas educacionais - PNAIC e PROUCA - para alfabetização no ensino fundamental de uma escola pública. 2015. Tese (Mestrado em Educação). Pontifícia Universidade Católica do Rio Grande do Sul, Porto Alegre. Disponível em: http://repositorio.pucrs.br/dspace/bitstream/10923/7084/1/000466414-Texto\%2BCompleto0.pdf Acesso em 10 maio 2016. 